\title{
Determining the optimum replacement policy for Holstein dairy herds in Iran
}

\author{
A. S. Kalantari, ${ }^{*}$ H. Mehrabani-Yeganeh, ${ }^{* 1}$ M. Moradi, ${ }^{*}$ A. H. Sanders, $\dagger$ and A. De Vries $\dagger$ \\ *Department of Animal Science, University of Tehran, Karaj, 4111, Iran \\ †Department of Animal Sciences, University of Florida, Gainesville 32611
}

\section{ABSTRACT}

The objective of this study was to determine the optimum replacement policy for Holstein dairy herds in Iran using a dynamic programming model. Cows were described in terms of state variables that included milk production class, parity, pregnancy status, and month in milk with a 1-mo stage length. The objective function maximized the net present value of cows over a 15-yr planning horizon. Markov simulation was used to estimate expected herd dynamics under the optimal decision plan determined by dynamic programming. Stochastic elements included probabilities of pregnancy and abortion, production level, and involuntary culling. The optimum annual culling rate was estimated to be $31.4 \%$, and cows had an expected herd life (time from first calving until culling) of 3.18 yr. High replacement cost and low carcass value resulted in only $2.87 \%$ voluntary culling (i.e., optimal model-based replacement). Assuming a heat detection rate of 0.4 , cows averaged 2.8 services per lactation under the optimal policy. Sensitivity analyses were carried out to evaluate the effect of milk price, herd-average production, feed cost, heifer price, and carcass value on optimum replacement decisions. Herd-average production, replacement cost, and risk of involuntary culling were important factors affecting the optimal culling policy. Changes in the price of feed, calves, and milk and the probability of pregnancy had no considerable effect on the optimal policy considering the market situation in Iran during 2008.

Key words: culling, optimization, dynamic programming

\section{INTRODUCTION}

Dairy production is a major agricultural sector in Iran's economy, and the Iranian dairy herd includes 842,000 Holstein cows on commercial dairy farms (Milk Industry, 2008). Although these farms are adequately

Received September 23, 2009.

Accepted February 1, 2010.

${ }^{1}$ Corresponding author: hmy1956@gmail.com equipped for modern dairy production, farmers face substantial economic challenges, making dairy farming a high-risk enterprise (Iran Ministry of Agriculture, 2006). The most important problems are volatility in milk prices and lack of financial support from the government (Mirzaei, 2006). Volatility results from a lack of coordination between input and output prices and inflation, which was over $25 \%$ for the period of 2005 to 2009 (CBIRI, 2009). Besides a lack of direct support from government, import policies allow the cheap import of meat, which reduces salvage values for culled dairy cows, whereas prices for replacement heifers are greater in Iran than in the United States.

Optimal replacement decisions are cited as one of the most important factors affecting farm profitability (van Arendonk, 1984), and these decisions are directly affected by fluctuations in milk price, salvage values, and replacement costs. The model used by DeVries (2006b) to optimize replacement under US conditions considers these factors, but results cannot be easily extrapolated to account for Iranian conditions. Culling decisions are based primarily on milk production and partially on health status. Despite their economic importance, culling decisions are often made in a nonprogrammed fashion and based partly on the intuition of the decision maker (Lehenbauer and Oltjen, 1998). Little or no effort is made to support replacement decisions using economic or financial methods.

Traditionally, culling of dairy cows has been viewed from a historical viewpoint. Many dairy farmers and their consultants calculate their annual culling rate and focus on the percentage of cows culled for a variety of reasons (Eicker and Fetrow, 2003). To improve culling decisions, a more prospective approach is preferable and could result in different culling decisions by producers. The ideal guide ranks all cows that are currently in the herd based on their future cash flows and suggests whether each cow should be kept or culled and replaced with a heifer (De Vries, 2006b).

Determining the optimal time to cull cows requires simultaneous accounting of several biological and economic variables. The most important factors considered in culling decisions are milk production level, pregnancy and health statuses, the stage of lactation, 
and the value of the potential replacement animal and its nominal cost. One technique for handling these variables is dynamic programming (DP).

Dynamic programming is a mathematical technique that divides a multistage problem into series of independently soluble, single-stage problems. In multistage optimization problems, DP has the advantage of determining optimal decisions without requiring exhaustive enumeration of all sequences of transition probabilities (DeLorenzo et al., 1992). A DP problem based on many state variables will still be complex to formulate. Burt (1982) suggested that the greatest obstacles to implementation of DP are conceptualization difficulties.

Several DP models have been developed to optimize dairy culling decisions (Smith, 1973; Stewart et al., 1977; Ben-Ari et al., 1983; van Arendonk, 1985b; Kristensen, 1988; Kennedy and Stott, 1993; De Vries, 2004), but they have not been used with production and market conditions in Iran. The objective of this study was to determine optimal replacement policy for Holstein dairy production systems in Iran following a modification of the approach used by van Arendonk (1985b).

\section{MATERIALS AND METHODS}

\section{DP and Simulation Models}

DP Model. A DP model was used to optimize dairy replacement decisions under Iranian market conditions during 2008. The objective function considered in this study was maximizing present values of net revenues from the present cow and replacement heifers over a 15-yr planning horizon with 1-mo stage length. A DP model as described by van Arendonk and Dijkhuizen (1985) was built and modified to incorporate the probability of pregnancy and abortion based on De Vries (2004, 2006a). The general formula for expected net present value of cows at stage $t$, following the notation of van Arendonk (1985b), is

$$
\begin{gathered}
F_{t}\left(\mathbf{X}_{t}\right)=\operatorname{Max}\left[\operatorname{Keep}_{t}\left(\mathbf{X}_{t}\right), \operatorname{Repl}_{t}\left(\mathbf{X}_{t}\right)\right] \\
t=(N-1, \ldots, 1)
\end{gathered}
$$

where

$$
\begin{aligned}
\operatorname{Keep}_{t}\left(\mathbf{X}_{t}\right)= & \delta\left\{R\left(\mathbf{X}_{t}\right)+\left[1-P I\left(\mathbf{X}_{t}\right)\right]\right. \\
& \times \sum_{m^{\prime}=1}^{15} P T\left(\mathbf{X}_{t}, m^{\prime}\right)\left[F_{t+1}\left(\mathbf{X}_{t+1}\right)\right] \\
& \left.+P I\left(\mathbf{X}_{t}\right)\left[S\left(\mathbf{X}_{t+1}\right)+F H_{t+1}\right]\right\},
\end{aligned}
$$

$$
\begin{gathered}
\operatorname{Repl}_{t}\left(\mathbf{X}_{t}\right)=S\left(\mathbf{X}_{t}\right)+F H_{t} \text {, and } \\
F H_{t}=-C+\delta \sum_{m=1}^{15} P H(m)\left\{R\left(\mathbf{X}_{t}\right)+\left[1-P I\left(\mathbf{X}_{t}\right)\right]\right. \\
\left.\times F_{t+1}\left(\mathbf{X}_{t+1}\right)+P I\left(\mathbf{X}_{t}\right)\left[S\left(\mathbf{X}_{t+1}\right)+F H_{t+1}\right]\right\},
\end{gathered}
$$

where $\operatorname{Keep}_{t}\left(\mathbf{X}_{t}\right)=$ expected net present value of cash flow given the initial state of the cow, the decision to keep at stage $t$, and an optimum policy during the remainder of the planning horizon; $\operatorname{Repl}_{t}\left(X_{t}\right)=$ expected net present value of cash flow given the initial state of the cow, the decision to replace at stage $t$, and an optimum policy during the remainder of the planning horizon; $F_{t+1}=$ expected net present value of cash flow for the cow from stage $t+1$ to stage $N ; F H_{t}=$ expected net present value of cash flow for a replacement heifer entered at stage $t$ to stage $N ; \mathbf{X}_{t}=$ vector representing the cow's state at stage $t ; R\left(\mathbf{X}_{t}\right)=$ net revenues during stage $t ; S\left(\mathbf{X}_{t}\right)=$ carcass value at the beginning of stage t; $P I\left(\mathbf{X}_{t}\right)=$ probability of involuntary culling at the end of stage $t ; \operatorname{PT}\left(\mathbf{X}_{t}, m^{\prime}\right)=$ probability of transition from milk production level $m$ in stage $t$ to production level $m^{\prime}$ in stage $t+1 ; P H(m)=$ probability of replacement heifer with production level $m$; $C=$ cost of a replacement heifer; $N=$ number of stages in the planning horizon; and $\delta=$ discount factor.

A schematic representation of model components is shown in Figure 1. Cow state was described with a vector of 4 state variables including parity $(1=1-12)$, milk production class $(\mathrm{c}=1-15)$, month after calving $(\mathrm{m}=$ $1-24)$, and pregnancy status $(\mathrm{n}=0-9$, where $\mathrm{n}=0$ for open cows or $n=$ month of pregnancy). Although this creates 43,200 total states, in actuality fewer than this are possible under biological and imposed constraints. For example, a cow cannot be 4 mo pregnant and only 2 mo since calving, or, with a voluntary waiting period of $60 \mathrm{~d}$, cows will not be pregnant in the first month after calving. Cows in pregnancy class 8 or 9 were considered dry. The transformation function, which defines the state of the process at the next stage, is dependent on the current state, the decision made at the current stage, and transition functions, which can be stochastic or deterministic. In this study, stochastic elements included the probability of conception if inseminated, the probability of survival (1 - probability of involuntary culling), and the probability of transition to a different milk production class in the next stage.

For this study, 2 economic indices were calculated: future profitability (FP) after van Arendonk (1985b), and retention pay-off (RPO) after De Vries (2004). The FP of a cow at stage $t$ is defined as 


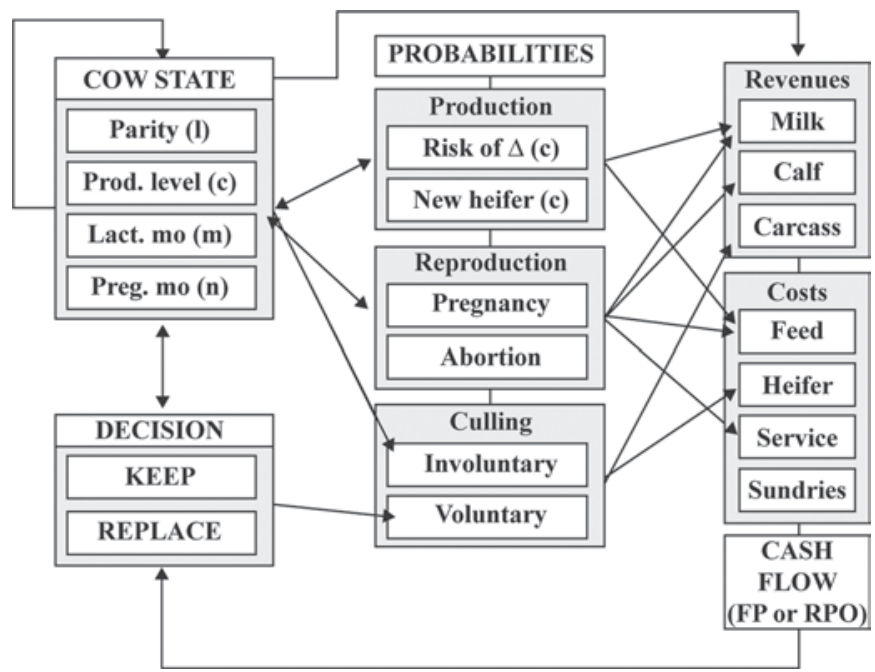

Figure 1. Schematic representation of model elements. Cow state is the vector of parity $(1=1-12)$, milk production class $(\mathrm{c}=1-15)$, months since calving $(\mathrm{m}=1-24)$, and months pregnant $(\mathrm{n}=0-9)$. FP $=$ future profitability; $\mathrm{RPO}=$ retention pay-off.

$$
\mathrm{FP}_{t}\left(\mathbf{X}_{t}\right)=\mathrm{F}_{t}\left(\mathbf{X}_{t}\right)-\operatorname{Repl}_{t}\left(\mathbf{X}_{t}\right),
$$

where $\mathbf{X}_{t}$ is the state vector of the cow at stage $t$, $\mathrm{F}_{t}\left(\mathbf{X}_{t}\right)$ is the value of the optimal decision at stage $t$, and $\operatorname{Repl}_{t}\left(\mathbf{X}_{t}\right)$ is the replacement value. Thus, when $\mathrm{FP}_{t}=0$, the optimal decision is to cull. Positive values represent the expected profit by keeping the cow until replacement is optimum instead of immediate replacement. The definition of RPO is

$$
\operatorname{RPO}_{t}\left(\mathbf{X}_{t}\right)=\operatorname{Keep}_{t}\left(\mathbf{X}_{t}\right)-\operatorname{Repl}_{t}\left(\mathbf{X}_{t}\right),
$$

where $\operatorname{Keep}_{t}\left(\mathbf{X}_{t}\right)$ is the expected value if the cow is retained at the present stage. Thus, $\mathrm{RPO}_{t}$ can take negative or positive values. A negative $\mathrm{RPO}_{t}$ represents the opportunity cost of keeping the cow in the herd until the next decision point. After running the DP model, it is possible to rank cows (i.e., states) by $\mathrm{FP}_{t}$ or $\mathrm{RPO}_{t}$ and use these ranking as decision criteria. One difference between $\mathrm{FP}_{t}$ and $\mathrm{RPO}_{t}$ is that all cows that the $\mathrm{DP}$ model determines should be culled have an $\mathrm{FP}_{t}$ of 0 , whereas these cows can be ranked by their negative $\mathrm{RPO}_{t}$ values. This ranking may be more useful in making culling decisions in some situations (Groenendaal et al., 2004). For instance, in the case where culling is constrained by the availability of replacements, it may be desirable to cull cows with the lowest $\mathrm{RPO}_{t}$ first.

Simulation Model. After determining the optimal solutions (keep vs. cull) for all states by DP, it is often desirable to be able to follow changes in cows and the cow herd over time. To do so, Markov chain simulation was used. The concepts of stages, states, and transi- tion are the same as in the DP model (Hardaker et al., 2004). The simulation method begins at the start of the planning horizon and works forward in time such that the state for each subsequent stage is determined by the current state, stochastic variables, and the decisions determined by DP.

In this model, the stochastic probabilities are the same as those defined for the transformation function in DP; namely, probabilities of involuntary culling, pregnancy and abortion, and transition to another production state. The probability that a cow exists in each state is determined by these probabilities, and the optimal decision to keep or cull a cow (that was not involuntarily culled) is identified by DP. The stage transition is iterated for a group of cows (i.e., herd) until the state probabilities become approximately stationary, at which time the herd is considered to be in steady state. The expected result of application of the determined policy can then be calculated for a variety of herd parameters.

Model Application. The DP and simulation models were developed as an executable program with Visual Basic (1998; Microsoft Corp., Redmond, WA). Input variables were entered and accessed and results collected in a spreadsheet. The model inputs and functions were defined from a performance model (described in the next section). Parameter values were calculated using data collected from 2 large dairy herds near Tehran, Iran. The herd records included parturition dates, culling dates and causes, and milking records for individual cows for 2008. The milking records were test-day production data collected at approximately monthly intervals by the Animal Breeding Center of Iran (Tehran). Additional parameters were based on literature and expert advice and were typical of Iranian test herds during the same period (2008).

\section{Performance Model}

The performance model is the bioeconomic representation of cows including costs such as feed, AI, and veterinary costs, and revenues such as milk production and calf and carcass values.

Costs. Spartan Ration Evaluator/Balancer for Dairy Cattle version 2 (Spartan Software Laboratory, 1992) was used to formulate 12 rations (fresh cows, 9 lactation stages, far-off and close-up dry stages), and NRC estimates of DMI were used to determine actual intake (based on BW as calculated above and production level; daily DMI for dry cows was assumed to be 12 $\mathrm{kg})$. This strategy modeled an optimal feeding strategy, effectively limiting the model sensitivity to suboptimal strategies, any number of which might be considered standard. Average veterinary costs per cow $(\$ 25)$ for a 
Table 1. Parameter values used in the base scenario, and similar figures for Pennsylvania taken from Groenendaal et al. (2004) and adjusted for inflation to 2008 prices

\begin{tabular}{lcc}
\hline & \multicolumn{2}{c}{ Value } \\
\cline { 2 - 3 } Input variable & Base scenario & Pennsylvania \\
\hline Price & $\$ 0.42 / \mathrm{kg}$ & \\
Milk & $\$ 350 /$ calf & $\$ 0.33 / \mathrm{kg}$ \\
Calf value $^{1}$ & $\$ 2.00 / \mathrm{kg}$ & $\$ 116 /$ calf \\
Carcass value & $\$ 3,000 / \mathrm{heifer}$ & $\$ 1.76 / \mathrm{kg}$ \\
Replacement heifer cost & $\$ 25 /$ cow-yr & $\$ 1,300 / \mathrm{heifer}$ \\
Veterinary cost & $\$ 5 / \mathrm{breeding}$ & $\$ 58 /$ cow-yr \\
Insemination cost & $\$ 20 /$ dose & $\$ 14 / \mathrm{breeding}$ \\
Semen cost & $\$ 5.63 / \mathrm{d}$ & $\$ 0.23 / \mathrm{kg}$ of DMI \\
Feed cost (lactation $)^{2}$ & $\$ 2.30 / \mathrm{d}$ & $\$ 0.17 / \mathrm{kg}$ of DMI \\
Feed cost (dry period) & $15 \%$ & $5 \%$ \\
Interest rate & & \\
${ }^{1}$ Average of male and female. & & \\
${ }^{2}$ Average cost based on all diets. & &
\end{tabular}

typical lactation were based on Iranian national statistics. Based on van Arendonk (1985a), 33\% of this cost was assigned to the first month, $11 \%$ to each of the second and third months, and the residual (45\%) to the remainder of the lactation. These and other costs or values are summarized in Table 1 along with some comparative numbers for Pennsylvania taken from Groenendaal et al. (2004).

Calf Value. For calculating calf value, it was assumed that all calves (male and female) are sold $1 \mathrm{wk}$ after they were born and cows were credited with revenue for a calf. It was also assumed that $50 \%$ of calves are heifers, and thus the amount credited was equal to the average value of heifer and bull calves (Meadows et al., 2005).

Carcass Value. The average live weight for each cow state (considering age and stage of lactation) was calculated by the Krover function described by van Arendonk (1985a). Birth weight was set at $42 \mathrm{~kg}$. To estimate more exactly the BW changes through time, the estimated live weight was fitted to the BW function described by NRC (2001). Carcass value was determined by estimated BW at the time of culling.

Milk Production. The incomplete gamma function (Wood, 1967) was used as the basis for estimating milk production throughout lactation. The incomplete gamma function is defined as

$$
y_{t}=a t^{b} e^{-c t}
$$

where $y_{t}$ is the yield on day $t$ after calving, $a$ is a scaling factor for initial yield, $b$ is a rate factor for the increase in yield to peak, and $c$ is a rate factor for the decline after peak. To obtain parameter estimates for Wood's lactation curves for first, second, and third or greater parities representative of Iranian herds, the NLIN pro- cedure of SAS (SAS Institute, 2005) was used. Data were 116,094 test-day records from the test herds. Parameters estimated are shown in Table 2 . The reported average herd production per cow in these herds was $11,583 \mathrm{~kg} / \mathrm{yr}$, and the cumulative $305-\mathrm{d}$ production calculated using the Wood's estimates for first, second, and third or greater parities were 9,869, 11,207, and $13,009 \mathrm{~kg}$, respectively. The 15 milk production classes were defined as described by van Arendonk (1985b), with production set to $69 \%$ in the lowest class of the base lactation curve and $130 \%$ in the highest class. The probabilities for transition from one production class to another were based on those used by Houben et al. (1994).

Involuntary Culling. Cows that would be kept for another stage based on the optimal DP solution had a chance of being culled involuntarily. The average probabilities of involuntary culling varied by parity and month after calving. The values used were those described by De Vries $(2004,2006 a)$. These values account for risk of death, and salvage value is discounted

Table 2. Parameter estimates for Wood's incomplete gamma function ${ }^{1}$ (Wood, 1967)

\begin{tabular}{lccc}
\hline & \multicolumn{3}{c}{ Parameter } \\
\cline { 2 - 4 } Parity & $a$ & $b$ & $c$ \\
\hline 1 & 17.15 & 0.198 & 0.002 \\
2 & 25.04 & 0.176 & 0.003 \\
$\geq 3$ & 27.02 & 0.222 & 0.004 \\
\hline
\end{tabular}

${ }^{1}$ Wood's incomplete gamma function: $y_{t}=a t^{b} e^{-c t}$, where $y_{t}$ is the yield on day $t$ after calving, $a$ is a scaling factor for initial yield, $b$ is a rate factor for the increase in yield to peak, and $c$ is a rate factor for the decline after peak. Parameters were calculated by the NLIN procedure of SAS (SAS Institute, 2005) using Iranian test herd data (116,094 test-day records from 2 herds). 
for this probability. These values did not include rulebased culling of cows open after 24 mo of lactation (reproductive culling) or after 12 lactations.

Reproduction. The voluntary waiting period was assumed to be $60 \mathrm{~d}$; thus, cows could not become pregnant in the first month after calving. Probabilities for pregnancy in first, second, and third or greater parities were 55,33 , and $15 \%$, respectively. These values were based on experience in typical Iranian herds, accounting for heat detection, breeding success, and early embryo loss. Probabilities of abortion by month of pregnancy were taken from Rafati (2008) and set to 3.58, 3.36, $3.27,2.49,1.66,1.67$, and $1.67 \%$ for the second through eighth months, respectively. Cows open after 14 mo of lactation were not eligible for breeding.

\section{Sensitivity Analysis}

After running the base scenario, sensitivity analyses were conducted to assess the effect of the price of replacement heifers, herd-average production, milk price, feed cost, carcass value, and interest rate on optimal replacement decisions.

\section{RESULTS AND DISCUSSION}

The average optimal herd life (time from first calving until culling) for the production and price circumstances described in the base scenario was 3.18 yr (38 mo). This is slightly longer than the average actual herd life in Iranian herds (32 mo). In this study we assumed that all cows were selling exclusively for slaughter. Cows sold to other farmers for production might affect average herd life. In Cardoso et al. (1999), selling cows exclusively for slaughter resulted in herd life of 55 mo, whereas selling some cows for production reduced average herd life to 44 mo.

Optimal annual replacement rate is the inverse of optimal herd life and the sum of the involuntary culling rate and the optimal voluntary culling rate. Involuntary culling is determined by rule (e.g., death, illness, or reproductive failure) and selective culling is based on the optimal decision to replace from the DP model. For the base scenario, the optimum annual replacement rate was $31.42 \%$, with an involuntary culling rate of $28.56 \%$ and optimal voluntary culling rate of only $2.87 \%$. High replacement cost and low carcass value in Iran (Table 1) result in this very low rate of voluntary culling given the rate of involuntary culling. Table 3 shows the expected voluntary culling rates within parity or production classes. Voluntary culling is proportionately greater in lower production classes. Voluntary culling is also proportionately less in first parity, peaks in second parity, and then generally declines slightly in later pari-
Table 3. Voluntary culling rates by milk production class (lowest production in class 1) or parity, weighted by average state probabilities (i.e., expected percentage of cows in this class)

\begin{tabular}{|c|c|c|}
\hline Item & $\begin{array}{c}\text { State } \\
\text { probability (\%) }\end{array}$ & $\begin{array}{l}\text { Weighted voluntary } \\
\text { culling rate }(\%)\end{array}$ \\
\hline \multicolumn{3}{|c|}{ Production class } \\
\hline 1 & 4.30 & 4.95 \\
\hline 2 & 2.24 & 3.40 \\
\hline 3 & 3.85 & 3.67 \\
\hline 4 & 5.69 & 3.40 \\
\hline 5 & 7.72 & 3.05 \\
\hline 6 & 9.51 & 3.65 \\
\hline 7 & 10.82 & 3.36 \\
\hline 8 & 11.32 & 3.15 \\
\hline 9 & 10.86 & 2.12 \\
\hline 10 & 9.57 & 2.11 \\
\hline 11 & 7.75 & 2.05 \\
\hline 12 & 5.74 & 2.10 \\
\hline 13 & 3.90 & 2.05 \\
\hline 14 & 2.28 & 1.77 \\
\hline 15 & 4.45 & 2.48 \\
\hline \multicolumn{3}{|c|}{ Parity } \\
\hline 1 & 31.72 & 1.81 \\
\hline 2 & 24.65 & 3.55 \\
\hline 3 & 17.88 & 3.41 \\
\hline 4 & 11.77 & 3.27 \\
\hline 5 & 7.03 & 3.06 \\
\hline 6 & 3.85 & 3.04 \\
\hline 7 & 1.90 & 2.84 \\
\hline 8 & 0.80 & 2.50 \\
\hline 9 & 0.28 & 2.19 \\
\hline 10 & 0.08 & 2.19 \\
\hline 11 & 0.03 & 2.94 \\
\hline $12^{1}$ & 0.01 & - \\
\hline
\end{tabular}

${ }^{1}$ All cows completing 12 lactations were selected for replacement.

ties. During first parity, calving-related health issues result in significant involuntary culling and relatively less voluntary culling because revenue is expected to increase in second parity with increased production. In second parity, overall culling rate is reduced and proportionately more voluntary culling is done based on accumulating production records. As cows age, voluntary cull decreases rapidly; cows that produce well enough to survive several lactations are likely to survive until they are culled involuntarily. These typical patterns are shown by the model despite the overall low proportion of involuntary culling, which is attributable to Iranian market parameters, the most important being high reproductive culling proportion of $34.9 \%$ (Mohammadi and Sedighi, 2009) and high heifer price, particularly relative to carcass value.

Culling was greater in open cows, reflecting the importance of pregnancy status in the optimal voluntary culling decision. This is despite the fact that no voluntary culling occurs in the first 9 mo of lactation because of high milk production. After those 9 mo, culling increased as milk production decreased until mo 23 and 24, when culling decreased again. At this stage, most open cows have already been culled because of 


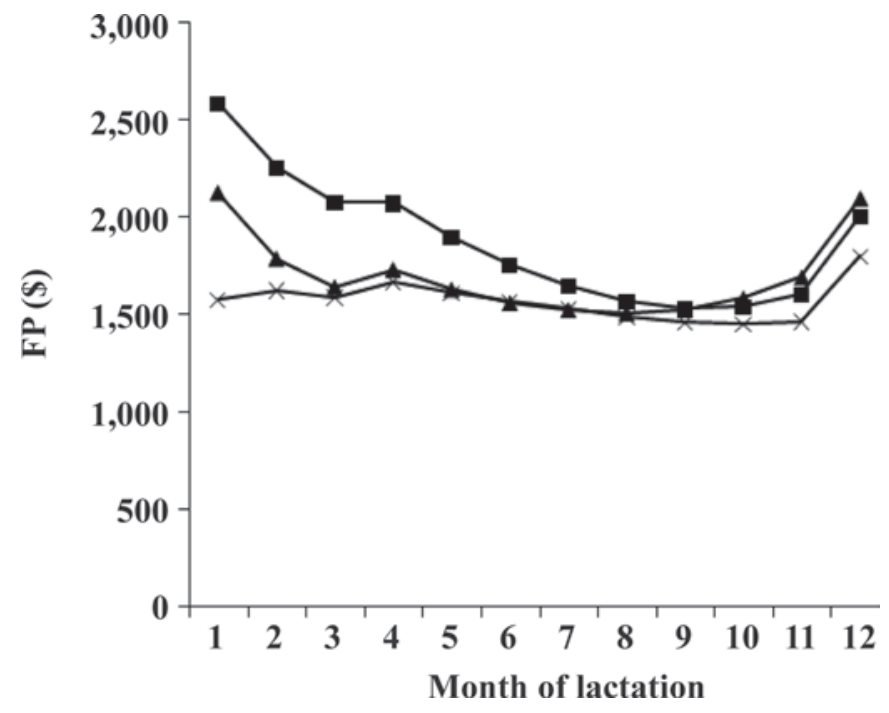

Figure 2. Future price (FP) by month of lactation for cows of average production class in first $(\times)$, second $(\boldsymbol{\Lambda})$, and third $(\boldsymbol{\square})$ parities and having a 12-mo calving interval.

low production, and pregnant cows are in late gestation and generally retained regardless of production because of the revenue (calf and lactation) expected at calving. Based on an expected heat detection rate of 0.4 , cows averaged 2.8 reproductive services per lactation. The model was consistent with test herd data and industry averages for days open (148 d) and calving interval (428 d).

The FP of cows varied by parity, milk production class, and stage of lactation. Figure 2 shows the FP across months of lactation for different parities consid- ering an average production class with a 12-mo calving interval. With exception of first-parity cows, FP were highest in early lactation. During first parity, FP was essentially flat. The increase in FP at the end of all lactations is attributable to expected calving revenues. Production level has a direct effect on FP. Figure 3 shows FP across months of lactation for third-parity cows in the third, eighth, and twelfth production classes (i.e., $25 \%$ below average, average, and $25 \%$ above average production). Although minimum FP is lower and decreases more steeply over months of lactation when calving interval is longer, the effect of production level is less.

Under the base situation, RPO varied between -\$184 (for an eleventh-parity cow, 9 mo pregnant, in the twentieth month of lactation and the lowest milk production class) and $\$ 3,520$ (for a third-parity open cow, in the first month of lactation and the highest milk production class). In the model used here, culling and replacement were unconstrained by availability of replacement, and herd size remained constant. Under these conditions, a cow with an RPO less than zero is culled and replaced. Using the same underlying assumptions, this policy will generate the same results as a policy using FP. Differences in RPO across months of lactation and parities are shown in Figure 4. A peak in RPO is seen in the first month lactations 2 through 10 , each followed by a steady decrease and then a sharp increase in anticipation of the subsequent calving. This shape is consistent with the FP value shown in Figures 2 and 3. The general decrease in RPO seen from the third to tenth parities is not attributable to production
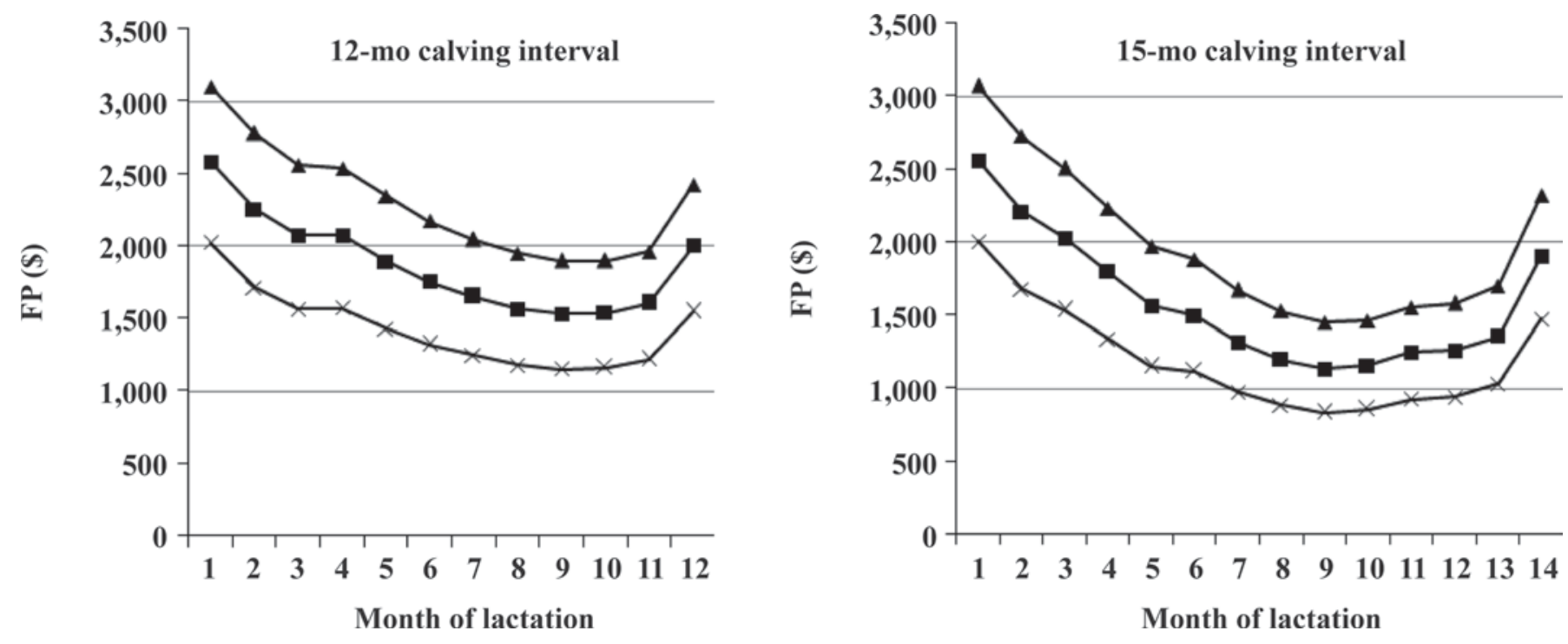

Figure 3. Future price (FP) by month of lactation for cows in third parity of average production $(\mathbf{\square})$, $25 \%$ below average production $(\times)$, and $25 \%$ above average production $(\mathbf{\Lambda})$ and having a 12 - or 15-mo calving interval. 


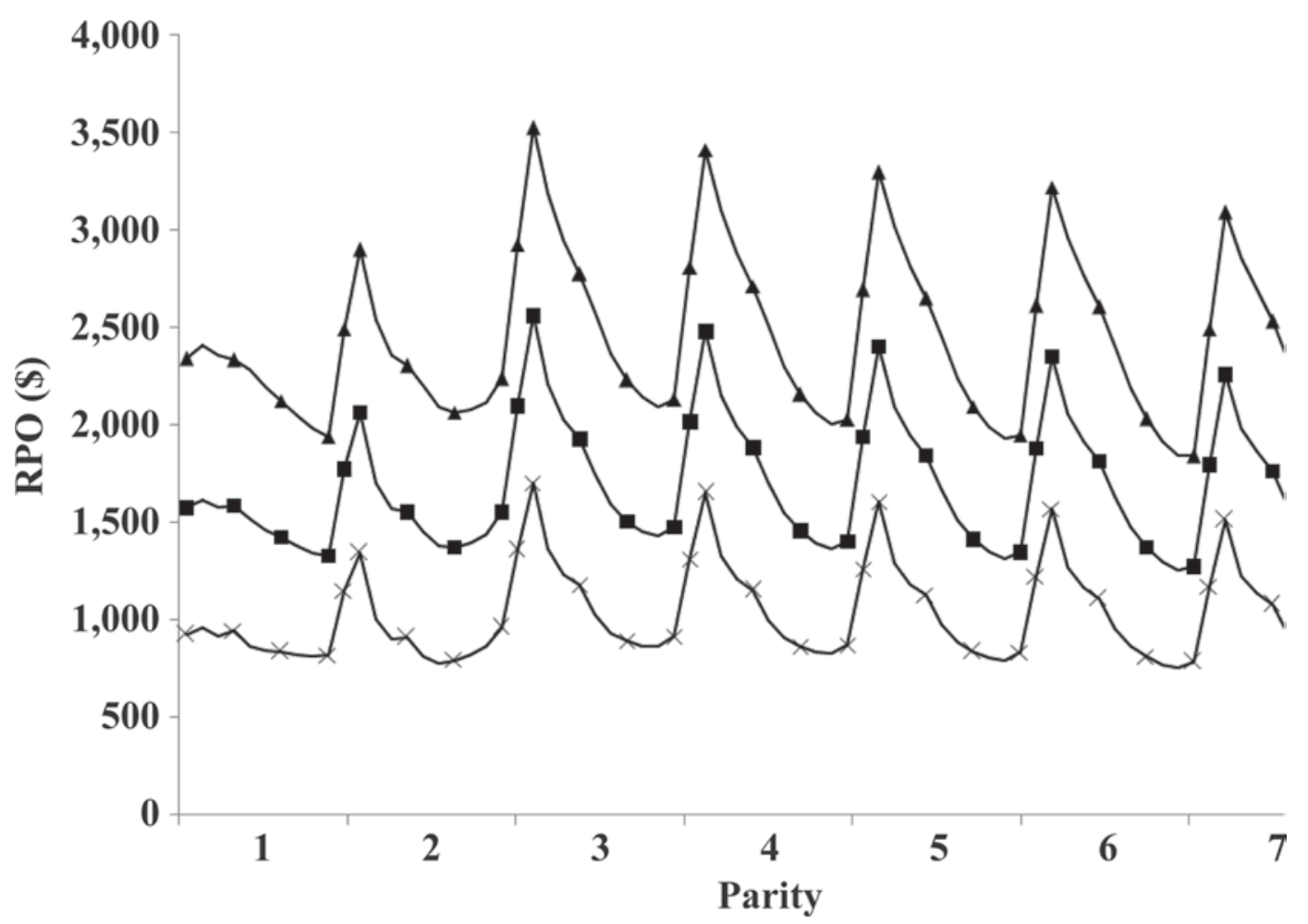

Figure 4. Average retention pay-off (RPO) by month of lactation across 10 lactations for cows of average production production $(\times)$, and $25 \%$ above average production $(\mathbf{\Lambda})$ and having a 12-mo calving interval.

because the same lactation parameters were used across these lactations. Instead, it is attributable to increasing risk of involuntary culling. The trend in decreasing RPO across lactations is in agreement with Groenendaal et al. (2004).

\section{SENSITIVITY ANALYSIS}

Changes in the price of a replacement heifer, herdaverage production, and involuntary culling had considerable effects on average herd life and replacement rate (Table 4). A $20 \%$ decrease in heifer price resulted in a shorter herd life and an $8 \%$ increase in replacement rate. The effect of heifer price on replacement rate has been previously reported (van Arendonk, 1985b; Cardoso et al., 1999; Rajala-Schultz et al., 2000), but was shown to be substantial only by Cardoso et al. (1999). The base scenario in this study reflected the high price of heifers in Iran, where farmers already tend to keep their cows as long as possible; thus, increasing heifer price had a limited additional effect. In previous studies (Stewart et al., 1977; van Arendonk, 1985b; van Arendonk and Dijkhuizen, 1985; Cardoso et al., 1999), the most important factor affecting replacement rate was the differential between carcass value and heifer price. At moderate heifer prices, increased carcass value results in increased voluntary culling and a higher overall replacement rate. As heifer price increases, however, the effect of carcass value diminishes. When heifer price reached $\$ 4,500$, the replacement rate was equal to the involuntary cull rate, no matter what the carcass price was (Figure 5). Changes in the value of milk, calves,

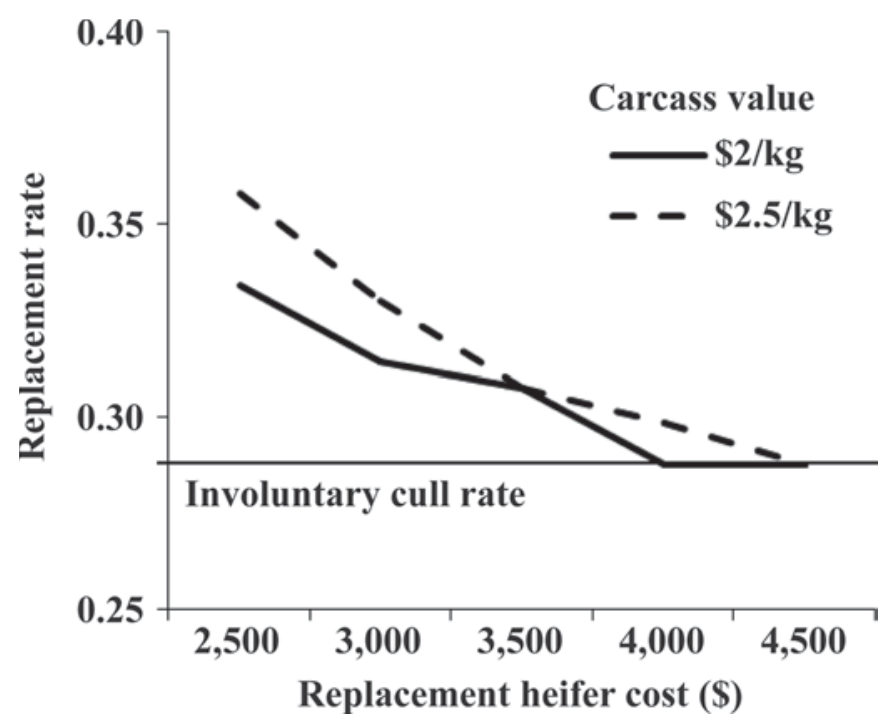

Figure 5. Optimal replacement rate for 2 levels of carcass price, considering increasing replacement heifer costs. 
Table 4. Effects of changes $( \pm 20 \%)$ in parameters on average herd life and replacement rate

\begin{tabular}{lccc}
\hline Parameter & Change $(\%)$ & Average herd life (yr) & Replacement/100 cows \\
\hline Basic scenario & & 3.18 & 31.42 \\
Herd-average production & +20 & 2.95 & 33.89 \\
& -20 & 3.46 & 28.92 \\
Calf value & +20 & 3.13 & 31.97 \\
Price of replacement heifer & -20 & 3.18 & 31.47 \\
Milk price & +20 & 3.28 & 30.47 \\
& -20 & 2.94 & 34.04 \\
Feed cost & +20 & 3.08 & 32.50 \\
Carcass price & -20 & 3.24 & 30.88 \\
& +20 & 3.17 & 31.50 \\
Involuntary culling & -20 & 3.17 & 31.56 \\
& +20 & 3.06 & 32.69 \\
& -20 & 3.24 & 30.83 \\
& +20 & 2.56 & 38.99 \\
\end{tabular}

feed, and carcass did not affect the optimum replacement rate to a great extent in this study.

The effects of the same $20 \%$ changes in parameters on average RPO is shown in Table 5. Average RPO indicates the average value of cows in the herd. As expected, changes in parameters that increased replacement rates (Table 4) resulted in decreased average RPO. Herdaverage production was an important factor for both average RPO and replacement rate, whereas milk price, calf value, and feed cost had limited to minimal effect. Replacement cost and carcass price had the greatest effects on RPO (along with herd-average production). Although involuntary culling had the greatest effect on replacement rate (as a direct component), it is less important in RPO.

\section{CONCLUSIONS}

A DP model was developed to determine the optimal replacement policy of cows under typical Iranian management and market conditions. The optimum replacement policy was substantially affected by the differential between replacement heifer price and the carcass value and by the herd-average production level. Although overall optimal replacement was more than
$30 \%$, most was because of involuntary culling. High replacement cost and low carcass value resulted in very little $(<3 \%)$ voluntary culling (i.e., based on an optimized decision). Cows were evaluated for replacement using FP value and RPO. Parity, stage of lactation, reproductive status, and milk production class influenced the RPO. Under price and production conditions in Iran, the RPO ranged from $-\$ 184$ to $\$ 3,520$. Changes in value of milk or feed, carcass, and calves had a negligible effect on optimum policies. This model demonstrates some unique constraints in the Iranian dairy industry and warrants further research into culling strategies under this system and how government interventions (e.g., tariffs on red meat, or preferential interest rates) might create greater opportunities for genetic progress.

\section{ACKNOWLEDGMENTS}

The authors express appreciation to A. Baniasadi for providing the data needed for this study, Anders Ringgaard Kristensen (Department of Large Animal Sciences, University of Copenhagen, Denmark) for providing direction in the use of dynamic programming, and M. Dehghan (Department of Animal Science, University of

Table 5. Effects of changes $( \pm 20 \%)$ in parameters on average retention pay-off (RPO)

\begin{tabular}{lrr}
\hline Item & \multicolumn{2}{c}{ Average RPO $(\$)$} \\
\hline Basic scenario & & 914 \\
Parameter changed & $+20 \%$ & $-20 \%$ \\
\hline Herd-average production & 735 & 1,075 \\
Calf value & 883 & 946 \\
Price of replacement heifer & 1,349 & 511 \\
Milk price & 871 & 964 \\
Feed cost & 923 & 906 \\
Carcass price & 742 & 1,091 \\
Involuntary culling & 841 & 993 \\
\hline
\end{tabular}


Tehran, Karaj, Iran) for his assistance in formulating the rations.

\section{REFERENCES}

Ben-Ari, Y., I. Amir, and S. Sharar. 1983. Operational replacement decision model for dairy herds. J. Dairy Sci. 66:1747-1759.

Burt, O. R. 1982. Dynamic programming: Has its day arrived? West. J. Agric. Econ. 7:381-394.

Cardoso, V. L., J. R. Nogueira, and J. A. M. van Arendonk. 1999. Optimal replacement and insemination policies for Holstein cattle in the southeastern region of Brazil: The effect of selling animals for production. J. Dairy Sci. 82:1449-1458.

CBIRI. 2009. Economic Trends. No. 54. Central Bank of the Islamic Republic of Iran, Tehran, Iran.

De Vries, A. 2004. Economics of delayed replacement when cow performance is seasonal. J. Dairy Sci. 87:2947-2958.

De Vries, A. 2006a. Economic value of pregnancy in dairy cattle. J. Dairy Sci. 89:3876-3885.

De Vries, A. 2006b. Ranking dairy cows for future profitability and culling decisions. Pages 91-109 in Proc. 3rd Florida and Georgia Dairy Road Show, University of Florida, Gainesville.

DeLorenzo, M. A., T. H. Spreen, G. R. Bryan, and D. K. Beede. 1992. Optimizing model: Insemination, replacement, seasonal production, and cash flow. J. Dairy Sci. 75:885-896.

Eicker, S., and J. Fetrow. 2003. New tools for deciding when to replace used dairy cows. Pages 33-46 in Proc. 2003 Kentucky Dairy Conference, Lexington, KY. University of Kentucky, Lexington.

Groenendaal, H., D. T. Galligan, and H. A. Mulder. 2004. An economic spreadsheet model to determine optimal breeding and replacement decisions for dairy cattle. J. Dairy Sci. 87:2146-2157.

Hardaker, J. B., R. B. M. Huirne, J. R. Anderson, and G. Lien. 2004. Coping with Risk in Agriculture. 2nd ed. CABI Publishing, Cambridge, MA.

Houben, E. H. P., R. B. M. Huirne, A. A. Dijkhuizen, and A. R. Kristensen. 1994. Optimal replacement of mastitic cows determined by a hierarchic Markov process. J. Dairy Sci. 77:2975-2993.

Iran Ministry of Agriculture. 2006. High risk in dairy industry. Annual Dairy Reports. [In Persian.] Iran Ministry of Agriculture, Tehran, Iran.

Kennedy, J. O. S., and A. W. Stott. 1993. An adaptive decision-making aid for dairy cow replacement. Agric. Syst. 42:25-39.

Kristensen, A. R. 1988. Hierarchic Markov processes and their applications in replacement models. Eur. J. Oper. Res. 35:207215.

Lehenbauer, T. W., and J. W. Oltjen. 1998. Dairy cow culling strategies: Making economical culling decisions. J. Dairy Sci. 81:264-271.
Meadows, C., P. J. Rajala-Schultz, and G. S. Frazer. 2005. A spreadsheet-based model demonstrating the nonuniform economic effects of varying reproductive performance in Ohio dairy herds. J. Dairy Sci. 88:1244-1254.

Milk Industry. 2008. Iran's Dairy Sector. http://milkindustry.net Accessed July 13, 2009.

Mirzaei, F. 2006. Future of agriculture in Iran: Case study-Animal products. Page 194 in Book of Abstracts from the 57th Annual Meeting of the European Association for Animal Production, Antalya, Turkey. Wageningen Academic Publishers, Wageningen, the Netherlands.

Mohammadi, G. R., and A. Sedighi. 2009. Reasons for culling of Holstein dairy cows in Neishaboor area in northeastern Iran. Iranian J. Vet. Res. 10:278-282.

NRC. 2001. Nutrient Requirements of Dairy Cattle. 7th ed. Natl. Acad. Press, Washington, DC.

Rafati, N. 2008. Prediction of the probability of abortion in dairy cows of Tehran region. MS Thesis. University of Tehran, Tehran.

Rajala-Schultz, P. J., Y. T. Gröhn, and H. G. Allore. 2000. Optimizing replacement decisions for Finnish dairy herds. Acta Vet. Scand. 41:185-198.

SAS Institute. 2005. SAS OnlineDoc. Version 9.1.3. SAS Institute Inc. Cary, NC

Smith, B. J. 1973. Dynamic programming of the dairy cow replacement problem. Am. J. Agric. Econ. 55:100-104.

Spartan Software Laboratory. 1992. Spartan Ration Evaluator/ Balancer for Dairy Cattle. Version 2. Michigan State University, East Lansing.

Stewart, H. M., E. B. Burnside, J. W. Wilton, and W. C. Pfeiffer. 1977. A dynamic programming approach to culling decisions in commercial dairy herds. J. Dairy Sci. 60:602-617.

van Arendonk, J. A. M. 1984. Studies in replacement policies in dairy cattle I. Evaluation of techniques to determine the optimum time for replacement and rank cows on future profitability. Z. Tierzucht. Züchtungsbiol. 101:330-340.

van Arendonk, J. A. M. 1985a. A model to estimate the performance, revenues and costs of dairy cows under different production and price situations. Agric. Syst. 16:157-189.

van Arendonk, J. A. M. 1985b. Studies on the replacement policies in dairy cattle. II. Optimum policy and influence of changes in production and prices. Livest. Prod. Sci. 13:101-121.

van Arendonk, J. A. M., and A. A. Dijkhuizen. 1985. Studies on the replacement policies in dairy cattle. III. Influence of variation in reproduction and production. Livest. Prod. Sci. 13:333-349.

Wood, P. D. P. 1967. Algebraic model of the lactation curve in cattle. Nature 216:164-165. 